\title{
Characteristics of Large Diffusion Flames Burning in a Vitiated Atmosphere
}

\author{
J. H. MOREHART, E. E. ZUKOSKI and T. KUBOTA \\ California Institute of Technology $301-46$ \\ Pasadena, California 91125 , USA
}

\begin{abstract}
Experiments concerning properties of large diffusion flames burning steadily in a vitiated atmosphere under conditions similar to those which may arise in a room fire are described. The effects of vitiation on the products of combustion and flame lengths, and the extinction limits are described for natural gas and ethylene diffusion flames stabilized on 8.9-, 19- and 50-cm pool-type burners. As vitiation was increased and the flame extinction limit was approached, the flame length increased slightly. Close to the limit, radiation from soot in the flame became imperceptible, leaving only a weakly luminous blue flame. Even with significant reductions in both the flame height and luminosity near the limit conditions, the hydrocarbon fuels were completely oxidized in the flame to water and carbon dioxide and no measurable concentrations of products of incomplete combustion were produced. A comparison of limiting oxygen concentrations and limiting flame temperatures for these experiments with the results of other investigations shows reasonably good agreement despite widely varying experimental techniques. These results are contrasted with those obtained in the unsteady situation which arises when a large buoyant diffusion flame burns in an enclosed space such that the upper part of the flame is in a strongly vitiated layer composed of a mixture of air and products of combustion, and the lower part in fresh air.
\end{abstract}

\section{INTRODUCTION}

Combustion in a room fire can occur in the three idealized modes. In the first mode, the flame is surrounded by unvitiated air. During the development of the fire in an enclosure, a stratified layer of vitiated gas may be formed at the ceiling and its thickness will grow in time if this space is not ventilated. The flame is in the second mode when the region of flaming combustion intrudes into this vitiated gas layer; then, part of the flame will entrain pure air and part vitiated gas. The third mode is reached when the vitiated ceiling layer descends below the base of the fire and the entire flame is immersed in an ambient gas which is vitiated. The properties of the flames and combustion products produced in these modes of combustion will depend on a number of parameters some of which are discussed by Zukoski [1]. 
In the first mode, the generation of incomplete combustion products is very small [2] and in the second, the generation of incomplete combustion products begins to be rapid [3-6] when the oxygen content of the upper layer falls below a mole fraction of roughly 0.05 . The aim of the present work was to study the combustion products produced by large, buoyant diffusion flames which burn in the third mode. We are also interested in the dependence of the flame length on the degree of vitiation and on the limiting oxygen concentration which will cause the extinction of some typical gaseous fuels stabilized on large burners used to model accidental fires.

The results discussed here involve experiments in which air is supplied to the top of a large hood at a steady rate and gaseous fuel, to a burner flame, again at a fixed rate. The burnt gas is removed from the hood at a level well below that of the burner surface and after the properties of the gas within the hood have reached a steady condition, the composition of the gas within the hood and the flame lengths are measured. This process is repeated until the flammability limit can be defined.

Many previous investigations of flammability limits of diffusion flames have been carried out $[7-14]$ and are reviewed elsewhere [15]. The new features of this work include the use of large-scale diffusion flames in a test in which some features of room fires are present, the dilution of the air with the products of combustion, and the determination in detail of the products of combustion and flame length as a function of the oxygen concentration up to the extinction limit.

\section{EXPERIMENTAL METHOD}

Gaseous fuel is supplied to a burner on which the fire is stabilized on a 5-cm deep porous bed of $6.3-\mathrm{mm}$ diameter spherical glass beads. Data is presented from experiments conducted with 8.9-, 19-, and 50-cm diameter burners of similar construction using natural gas fuel. The burner surface is submerged into the interior volume of a bare-metal hood measuring $1.83-\mathrm{m}$ square by $1.83-\mathrm{m}$ tall. Air is supplied near the top of the hood through a network of $2.54 \mathrm{-cm}$ diameter copper supply lines with 365 evenly spaced $1.6-\mathrm{mm}$ diameter holes on $2.54-\mathrm{cm}$ centers and products of combustion escape from the open bottom of the hood. The injected gas is aligned with the mean streamline of the plume induced flow. Excess combustion products mixed with the added air are allowed to spill out beneath the edges of the hood and thus produce a well-defined interface between the recirculating vitiated gases inside the hood and the cool, uncontaminated room air. In these experiments, the burner surface is positioned at least $30 \mathrm{~cm}$ above this interface.

Gas samples are continuously withdrawn through a $9.5-\mathrm{mm}$ diameter stainless steel tube inserted into the upper layer at an elevation roughly in the middle of the hood between the air addition network and the burner surface. An aspirated chromelalumel thermocouple is mounted at the entrance of the probe and is shielded from external radiation. Experiments have shown that the composition of the gases within the hood are uniform over all elevations and that a slight vertical temperature gradient exists both with and without air addition [6]. Gas samples withdrawn from the hood are carried by a $6.4-\mathrm{mm}$ copper line to an ice bath where the water vapor is removed, followed by a $0.1-\mu \mathrm{m}$ filter for the removal of soot particles from the sample. The sample is then fed directly into the sample loop of a gas chromatograph for analysis. 
More details about the chromatographic technique can be found in [6]. Results of tests with methane (natural gas) and ethylene will be reported here.

Measurements were taken in natural gas fires ranging from 15 to $31 \mathrm{~kW}$ and ethylene fires from 14 to $20 \mathrm{~kW}$. The experimental technique was to adjust the fuel flow rate to provide the largest flame height which would not extend into the air addition region of the hood. The air addition rate was set to provide more than enough air to support the combustion of the fuel. After allowing the composition and temperature inside the hood to reach a steady state (at least 25 to 30 minutes), a chemical sample and a two-minute video movie at 30 frames per second were taken. The fuel flow rate was then incrementally increased and the measurement process described above was repeated until further increases in the fuel flow rate would cause the extinction of the fire. Finally, after holding conditions very close to extinction for 20 minutes, a final data set was obtained. Changes in fuel-air parameters were made smaller as the flame extinction limit was approached and the value of the oxygen mole fraction at the limit was determined with an uncertainty of less than $1 \%$.

Flame lengths were obtained by making measurements of instantaneous flame length and defining the time-averaged flame length as the distance above the burner such that the flame spent $50 \%$ of the time at larger and smaller heights.

\section{RESULTS AND DISCUSSION}

Flame Characteristics: As the oxygen mole fraction was decreased and conditions approached the limit of flammability, soot production in the flame stopped and very close to the limit, lifted flames were observed.

The most striking observation of these fires near the limit of flammability was that radiation from soot in the reaction zone became imperceptible, and the regions of combustion were marked only by a weakly luminous blue flame. However, even extended periods of burning at these conditions did not produce an observable deposit of soot on the hood's interior, nor was the presence of soot detected in the $0.1-\mu \mathrm{m}$ filter of the sample line. This behavior has been documented in previous studies for both diffusion flames [9], and premixed flames near extinction [2].

Measurements of the heat release rates in premixed methane and ethane fires by Tewarson [12] showed that 93 to $95 \%$ of the heat release was convective when the flames were "non-luminous," in comparison with values of 50 to $75 \%$ convective heat release when soot was produced. The absence of visible radiation from soot in the flames and the complete suppression of soot production are most probably due to a decrease in the temperature of the reaction zone as the degree of vitiation is increased.

Near the limit condition, the flames lifted from the burner surface and were typically attached to only a small portion of the burner rim; flame geometry and attachment fluctuated strongly. In the case of the ethylene fires it was possible to adjust the fuel flow rate so that the burning was no longer stabilized on the burner bed, but was stabilized at a distance of 10 to $15 \mathrm{~cm}$ above the burner surface.

Combustion Products: Experiments were carried out with $8.9-, 19-$ and 50-cm diameter burners with natural gas fuel and with the $19-\mathrm{cm}$ burner for the ethylene fuel. In all of the experiments using natural gas and ethylene fuel the concentration of carbon dioxide and water were present in stoichiometric proportions and no unburnt fuel, carbon monoxide or other product of incomplete combustion could be measured 
even for condition closest to the limit of flammability when soot production had been stopped and lifted flames were observed.

The chromatographic technique employed here allowed the measurement of concentrations less than 250 parts per million for these species so their production rates even in the most extreme condition was small. These results show that despite the gross changes observed in the character of the fire, the combustion of the natural gas and ethylene was complete at least to the limitations of our measurement technique. Tewarson [2] also found negligibly small amounts of carbon monoxide and total hydrocarbons in the product gases of non-luminous premixed methane and ethane flames near extinction.

Product-layer gas temperatures in the experiments using natural gas fuel ranged from 120 to $240 \circ \mathrm{C}$ and those for ethylene ranged from 1.05 to $155 \circ \mathrm{C}$. In both cases, as the fuel flow rate was increased and limiting conditions were approached, the temperature of the product gases within the hood continued to increase. We believe this was due not only to an increase in the rate of chemical energy release, from the increased fuel flow rate, but also from a reduction in energy losses by radiation from the soot.

At conditions nearest extinction, it was possible to adjust the fuel flow rate so that the non-luminous ethylene flames were balanced 10 to $15 \mathrm{~cm}$ above the burner surface. With no alteration to the fuel or air addition rates, it was possible to maintain this limiting condition much longer than the residence time of the gas within the hood (based on fluid-mechanical considerations). In contrast, when natural gas fires at limiting conditions detach from the burner surface, the flames travel slowly upward away from the burner by as much as 3 to 4 burner diameters (for the 19-cm diameter burner) before complete extinction occurs. Lockwood [13] reported similar observations for methane and propane fueled fires driven close to the extinction limit by the addition of nitrogen gas to the air and attributed this behavior to the flame following a region of hot gas with greater oxygen content. Even under these extreme conditions, no unburnt fuel was observed in the product gases.

Flame Length: Measurements are being made of the effects of vitiation on the lengths of diffusion flames burning in a vitiated atmosphere. Elementary analysis often assume that the length of the flame is fixed by the distance required to entrain an amount of oxygen which corresponds to some multiple of that required to produce a stoichiometric fuel-air mixture in the fire plume. This simple idea suggests that the flame length should increase with the degree of vitiation and should be increased by factors up to 2 for conditions near the extinction limits.

However, our current measurements show that the flame length increases very slowly as the degree of vitiation approaches the flammability or stability limit. Timeaveraged flame lengths were found to be a linear function of oxygen mass fraction and the decreased about $5 \%$ as the mass fraction of oxygen increased from the extinction limit to the value in air. This increase with increasing oxygen content was not temperature dependent for ambient gas temperatures in the 300 to $600 \mathrm{oK}$ range. This discussion of flame lengths does not include lifted flames which were observed near limit phenomena, but does include flames in which no soot was formed.

The observed trend of the flame length data may be accounted for at least in part 
by the reduced relative buoyancy of the fire plume which results from the increased temperature of the ambient gas. For example, when the gas temperature in the hood is increased from 300 to $600 \mathrm{oK}$ the ratio of the density of the ambient gas to the mean density of the gas within the plume is decreased by roughly a factor of 2 .

Extinction Limits: Extinction limits were determined for the 8.9-, 19- and 50$\mathrm{cm}$ diameter burners with natural gas fuel and with the 19-cm burner for the ethylene fuel by the method described above. The results, given as the mole fraction of oxygen in the vitiated atmosphere at the limit are tabulated in Table 1 for natural gas and ethylene fuels, and are compared with results obtained in other and quite different experiments in Tables 2 and 3 .

TABLE 1. Comparison of Measurements for Methane Fires

\begin{tabular}{lcccccc}
$\begin{array}{l}\text { Fuel } \\
\text { type }\end{array}$ & $\begin{array}{l}\mathrm{D} \\
\mathrm{cm}\end{array}$ & $\begin{array}{l}Q_{c} \\
\mathrm{~kW}\end{array}$ & $\begin{array}{l}\dot{m}_{\text {air }} \\
\mathrm{g} / \mathrm{s}\end{array}$ & $\begin{array}{l}\dot{m}_{\text {fuel }} \\
\mathrm{g} / \mathrm{s}\end{array}$ & $\begin{array}{l}\mathrm{Ta} \\
\mathrm{K}\end{array}$ & $\begin{array}{c}Y_{\mathrm{O}_{2}} \\
\text { mole fr. }\end{array}$ \\
\hline Natural & 8.9 & 23 & 27.9 & 0.49 & 464 & 0.143 \\
$\quad$ gas & 19 & 28 & 27.4 & 0.59 & 472 & 0.132 \\
& 50 & 37 & 34.5 & 0.77 & 512 & 0.124 \\
Ethylene & 19 & 14 & 8.3 & 0.29 & 409 & 0.106 \\
\hline
\end{tabular}

Note: $\mathrm{D}$ is the burner diameter and the flow parameters at the extinction limit are: $Q_{c}$, the chemical heat release rate of the fire based on the fuel flow rate; $\dot{m}_{\text {air }}$ and $\dot{m}_{\text {fuel }}$, the air and fuel flow rates to the hood; Ta, the temperature of the ambient gas; and $Y_{\mathrm{O}_{2}}$, the mole fraction of oxygen.

TABLE 2. Comparison of Measurements for Methane Fires

\begin{tabular}{lllll}
\hline Diluent & Limit $\mathrm{O}_{2}$ & Limit Temp & Burner Size & Ref \\
\hline Combustion & 0.1242 & $1492^{\circ} \mathrm{C}$ & $50 \mathrm{~cm} \mathrm{dia}$ & Present \\
Products & 0.1321 & $1564^{\circ} \mathrm{C}$ & $19 \mathrm{~cm} \mathrm{dia}$ & Study \\
& 0.1428 & $1655^{\circ} \mathrm{C}$ & $8.9 \mathrm{~cm} \mathrm{dia}$ & \\
Nitrogen & 0.121 & & Premixed & {$[7]$} \\
& 0.129 & & Premixed & {$[8]$} \\
& 0.139 & $1518^{\circ} \mathrm{C}$ & 1.6 to $4.1 \mathrm{~cm}$ dia & {$[9]$} \\
& 0.1446 & $1538^{\circ} \mathrm{C}$ & 25 to $30 \mathrm{~cm}$ dia & {$[13]$} \\
Carbon & 0.146 & & Premixed & {$[7]$} \\
Dioxide & 0.157 & & Premixed & {$[8]$} \\
& 0.1789 & $1500^{\circ} \mathrm{C}$ & 25 to $30 \mathrm{~cm}$ dia & {$[13]$} \\
Argon & 0.1275 & $1574{ }^{\circ} \mathrm{C}$ & 25 to $30 \mathrm{~cm}$ dia & {$[13]$} \\
\hline
\end{tabular}


TABLE 3. Comparison of Measurements for Ethylene Fires

\begin{tabular}{lcclc}
\hline Diluent & Limit $\mathrm{O}_{2}$ & Limit Temp & Burner Size & Ref \\
\hline Combustion & 0.1060 & $1490{ }^{\circ} \mathrm{C}$ & $19 \mathrm{~cm}$ dia & $\begin{array}{l}\text { Present } \\
\text { Study }\end{array}$ \\
Products & & & & \\
Nitrogen & 0.100 & & Premixed & {$[7]$} \\
& 0.100 & & Premixed & {$[8]$} \\
& 0.105 & $1335{ }^{\circ} \mathrm{C}$ & 1.6 to $4.1 \mathrm{~cm} \mathrm{dia}$ & {$[9]$} \\
Carbon & 0.117 & & Premixed & {$[7]$} \\
Dioxide & 0.124 & & Premixed & {$[8]$} \\
\hline
\end{tabular}

The present experiment measures the limiting condition at which a diffusion flame could be stabilized on the burner and hence could also be described as a stability limit rather than a flammability limit. Unfortunately, making a meaningful distinction between these two phenomena is very difficult and is a common problem for many of the methods used to determine flammability limits for diffusion flames since flowing streams of air are usually used [7-10]. Consequently, extinction or flammability limits for diffusion flames do depend on the type and scale of the apparatus, and flow velocities used in the tests. For example, see the discussions in Simmons and Wolfhard [9] and in the review article of Coward and Jones [8]. Given small fuel velocities at the burner surface (as low as $3 \mathrm{~mm} / \mathrm{s}$ for the $50-\mathrm{cm}$ burner) and the corresponding low momentum flux of the fuel and entrained ambient gas used in these tests, we expect that the influence of these fluid dynamic parameters is not larger in these tests than for other methods.

Measurements made with small-scale techniques also have shown that the limits depend on the temperature and humidity of the ambient atmosphere $[8,9]$ and these parameters were not controlled in the experiments discussed here. The humidity of the vitiated atmosphere used in the current tests depends primarily on the degree of vitiation and not on the moisture present in the unvitiated atmosphere. The temperature of the ambient atmosphere in the hood ranged from 400 to $500 \circ \mathrm{K}$, and was high enough to produce some variation in the limits. This temperature dependence is being investigated.

The test conditions at the extinction limit for three examples are given in detail in Table 1. As expected, the limits do depend on burner scale, compare the 8.9- and $19-\mathrm{cm}$ burner data for natural gas, and may also depend on the temperature of the ambient gas. For example, extinction limits for natural gas decrease as burner size increase. For these three tests, the initial momentum flux of the fuel decreased by a factor of about 12 and thus the limits obtained were not a sensitive function of the momentum flux. Other fluid dynamic parameters which changed as the diameter is changed were the fluid velocity and the radiant heat transfer to the burner surface, which may also play a role by influencing the burner temperature and hence the initial buoyancy of the fuel.

Comparisons of the measurements of the present study to those of other investiga- 
tions are presented in Tables 2 and 3 for methane and ethylene fuels, respectively. The limiting oxygen measurements are expressed in terms of mole fractions and correspond to the most fuel-rich conditions which continued to support the combustion process. Assuming that under limiting conditions the fuel and oxidant meet in stoichiometric proportions in the reaction zone of a diffusion flame, a limiting flame temperature can be approximated by the adiabatic flame temperature for a stoichiometric mixture of fuel and vitiated gases. Experiments by Diedrichsen and Wolfhard [16] have shown that the error introduced by this approximation is small.

Our limiting oxygen measurements for the methane fires show good agreement with the other measurements taken in nitrogen diluted environments, and less so when other diluents are used. This result is reasonable since the composition of the diluent gases in our vitiated environment was primarily nitrogen $\left(85 \% \mathrm{~N}_{2}, 10 \% \mathrm{H}_{2} \mathrm{O}, 4 \% \mathrm{CO}_{2}\right.$, and $1 \% \mathrm{Ar}$ for the limiting experiment with the $19-\mathrm{cm}$ diameter burner) and hence the specific heats of the mixture are not greatly different from that of nitrogen. Differences in the limiting flame temperatures may be due to the presence of some water vapor and carbon dioxide in the oxidant supporting the combustion. The results of the experiments with ethylene fuel agree remarkably well for all of the studies listed in Table 2, despite the widely varying experimental techniques. Again, differences in the limiting flame temperatures may be due to the water vapor and carbon dioxide content of the vitiated environment.

These results suggest that flammability measurements taken in small-scale laminar flames can be used as a good first approximation to flammability limits for large diffusion flames burning in vitiated atmospheres produced in accidental fires. The extent of the agreement between the measurements of this study and those of other experimental approaches is encouraging, however, the limited evidence with these simple fuels may not be indicative of more complex fuels and small-scale measurements for the purposes of predicting large-scale behavior should be used with caution. In particular the dependence on ambient gas temperature needs to be clarified.

\section{APPLICATIONS TO FIRE MODELS}

The three modes of burning identified in the above discussion were steady state situations which were not influenced by the development of the upper, vitiated layer. The growth of thickness of the vitiated layer in an enclosure fire, which fixes the times for transition from modes 1 to 2 and then to 3 , depends in detail on the ventilation of the enclosure, the room geometry, heat transfer to the walls, and the location and growth rate of the fire. Considerable concentrations of incomplete products of combustion may be produced when combustion occurs in mode 2 and the simple picture of extinction, presented by our discussion of the steady state fires, must be examined to determine whether or not it is applicable to more realistic situations.

For the gaseous fuels we have studied, the production of incomplete combustion products does not occur in mode 2 until the concentration of oxygen in the upper layer falls below 0.05 mole fraction where as the extinction limit is reached when the mole fraction is still above roughly 0.12 . Thus, the flame will only continue to burn after the transition between Regimes 2 and 3 when concentrations of incomplete combustion in the upper layer are still very small. For these fires the discussion of extinction given above appears to be valid. Should the concentration of oxygen in the layer be less than 
0.05 mole fraction, products of incomplete combustion will be generated in mode 2 , but the extinction of the flame will occur as soon as the interface passes a short distance below the base of the flame. Hence, the presence of incomplete combustion products in the vitiated gas will not affect the extinction process as long as the entrainment of air from below the interface is stopped by the passage of the interface.

Thus, the key issue concerning extinction is not the presence or absence of incomplete combustion products in the upper layer, but the interruption of the entrainment of oxygen from beneath the interface. Preliminary measurements suggest that this entrainment continues until the interface is one half to one diameter below the base of the burner. However, this issue is still being investigated.

For some conditions of ventilation, the transition between modes 2 and 3 will occur very slowly and the interface will remain close to the base of the flame rather than moving rapidly below it. This possibility exists because of the very strong interaction between the level of the interface relative to the base of the fire and parameters controlling the pyrolysis rate of solid or liquid fuels, the heat release rate of the fire, and the ventilation of the upper layer. Under some conditions, the level of the interface has been observed to oscillate about the base of the flame without causing extinction. This condition can cause combustion to occur under the conditions corresponding to mode 2 and large concentrations of incomplete combustion products will be produced. For these conditions, our model for extinction will not be applicable because the interface level will not clearly descend below the base of the fire to shut off entrainment from the lower layer.

\section{CONCLUSIONS}

Natural gas (primarily methane) and ethylene fires burning in reduced-oxygen environments with conditions near the limit of flammability were investigated. Despite significant changes in the characteristics the flames, the combustion process was complete even under limiting conditions. As the vitiation of the ambient atmosphere and its temperature were increased and extinction conditions were approached, flame heights increased slightly. Near the limit, the radiation from soot particles disappeared and soot production was apparently suppressed.

Measurements of chemical species produced in fires at the extinction limit showed that levels of residual fuel and carbon monoxide were always less than 250 parts per million.

A comparison of experimental measurements of the limiting oxygen concentrations for premixed flames, small-scale diffusion flames, and large-scale diffusion flames suggests that minimum oxygen levels required to sustain combustion are primarily dependent on the fuel type and diluents present, and are much less sensitive to the burner configuration. Flammability results obtained in small- scale flames with nitrogen as a diluent are similar to those obtained here in large-scale tests when air mixed with combustion products was used as the ambient fluid.

The results obtained here can be used in two-layer room-fire models as long as the interface, separating the upper vitiated layer and lower unvitiated layer, moves past the base of the fire far enough to shut off the entrainment of oxygen from the lower layer into the fire plume. 


\section{REFERENCES}

[1] Zukoski, E. E., "Fluid Dynamic Aspects of Room Fires," First Int'l Symp. on Fire Safety Sci., Tokyo, Japan, 27, 1-32, 1986.

[2] Tewarson, A., "Heat Release Rates From Burning Plastics," J. Fire and Flamm., 8, 115-130, 1977.

[3] Cetegen, B. M., Zukoski, E. E., and Kubota, T., "Entrainment in the Near and Far Field of Fire Plumes," Comb. and Fl., 39, 305-331, 1984.

[4] Beyler, C. L., Development and Burning of a Layer of Products of Incomplete Combustion Generated by a Buoyant Diffusion Flame, Ph.D. Thesis, Harvard University, 1983.

[5] Toner, S. J., Entrainment, Chemistry, and Structure of Fire Plumes, Ph.D.Thesis, California Institute of Technology, 1986.

[6] Zukoski, E. E., Morehart, J. H., Kubota, T., and Toner, S. J., "Species Production and Heat Release Rates in Two-Layered Natural Gas Fires," submitted to Comb. and $F l, 1990$.

[7] Jones, G. W. and Kennedy, R. E., "Prevention of Gas Explosions by Controlling Oxygen Concentration," Ind. Eng. Chem., 27, 1344-1346, 1935.

[8] Coward, H. F. and Jones, G. W., "Limits of Flammability of Gases and Vapors," Bull. U.S. Bur. Min., 50, 1952.

[9] Simmons, R. F. and Wolfhard, H. G., "Some Limiting Oxygen Concentrations for Diffusion Flames in Air Diluted with Nitrogen," Comb. and Fl., 1, 155-161, 1957.

[10] Fenimore, C. P. and Martin, F. J., "Flammability of Polymers," Comb. and Fll, 10, 135-139, 1966.

[11] Nelson, G. L. and Webb, J. L., "Oxygen Index of Liquids Technique and Application," J. Fire and Flamm., 4, 210-226, 1973.

[12] Tewarson, A. and Pion, R. F., "Flammability of Plastics - I. Burning Intensity," Comb. and Fl., 26, 85-103, 1976.

[13] Lockwood, W. R., Inert Suppression of Enclosure Fires, Ph.D. Thesis, University of Washington, 1986.

[14] McCaffrey, B. J. and Harkleroad, M., "Combustion Efficiency, Radiation, CO and Soot Yield from a Variety of Gaseous, Liquid, and Solid Fueled Buoyant Diffusion Flames," 22nd Int'l Symp. on Comb., The Combustion Institute, Pittsburgh, PA, 1251-1261, 1988.

[15] Morehart, J. H., Zukoski, E. E. and Kubota, T., "Chemical Species Produced in Fires Near the Limit of Flammability," to be published in Comb. and Fl., 1990.

[16] Diedrichsen, J. and Wolfhard, H. G., "Spectrographic Examination of Gaseous Flames at High Pressure," Proc. Roy. Soc.," A 236, 89-103, 1956. 
